\section{¿Heparina o prednisona para la prevención del aborto espontáneo?}

Aunque el diagnóstico diferencial en el caso de abortos espontáneos recurrentes abarca un amplio espectro de anormalidades anatómicas y genéticas, la presencia de autoanticuerpos puede ser un factor causal ocasional. De estos autoanticuerpos, los antifosfolípidos han sido el tema de dos artículos publicados en The New England Journal of Medicine, según comenta un editorial correspondiente al mismo número de esa revista. Rand et al. han observado que los anticuerpos antifosfolípidos provocan un descenso de las concentraciones de anexina $\mathrm{V}$, factor de superficie anticoagulante detectable en cultivos de células vasculares y trofoblásticas. Cuando estas células, después de haber sido incubadas con dichos anticuerpos, se colocan en contacto con plasma, el tiempo de formación de la fibrina se acorta. La posibilidad de que los autoanticuerpos antifosfolípidos actúen exclusivamente según un mecanismo procoagulante plasmático y de que por ese medio favorezcan la trombocitopenia y la trombosis requiere mayor confirmación.

Las tres pacientes evaluadas por Rand et al. tenían antecedentes de trombosis recurrente y de abortos múltiples. Consiguientemente, no se puede concluir que la presencia de autoanticuerpos sea causa de aborto en mujeres sin esos antecedentes clínicos ni datos de laboratorio indicadores de coagulación acelerada. No obstante, los estudios efectuados in vitro confirmaron los efectos trombógenos de los autoanticuerpos, ya conocidos anteriormente por favorecer una activación endotelial manifestada por 1) regulación intensificada de la expresión de moléculas adherentes, 2) secreción de citoquinas antiinflamatorias y 3) modulación del metabolismo del ácido araquidónico. Por otra parte, otros estudios clínicos sugieren que hay, como mínimo, un subgrupo de mujeres con abortos recurrentes y presencia de anticuerpos antifosfolípidos en quienes estaría indicada la heparina como anticoagulante.

En el segundo artículo, Laskin et al. presentan los resultados de un ensayo aleatorio en que se administró prednisona a mujeres gestantes con antecedentes de abortos espontáneos o de muerte fetal. La prednisona no dio resultado, ya que no aumentó el número de hijos nacidos vivos de las mujeres con anticuerpos antifosfolípidos.

Según Cowchock, los dos estudios proveen información válida, pero no permiten llegar a conclusiones generales sobre el tratamiento de mujeres con abortos recurrentes. Los anticuerpos antifosfolípidos serían uno de los diversos factores de riesgo que predisponen a la trombosis, junto con otras anormalidades coexistentes de la coagulación, tales como una baja concentración plasmática de proteína $\mathrm{S}$ y mutaciones del factor $\mathrm{V}$ de Leyden. No obstante, es probable que el tratamiento con heparina esté indicado cuando hay pruebas de coagulación acelerada y de su posible asociación con amenaza de aborto. En las otras mujeres gestantes se sigue recomendando el tratamiento con prednisona o inmunoglobulina, hasta tanto se compruebe o no su eficacia mediante ensayos rigurosos en grupos de mujeres con antecedentes clínicos similares, signos de trastorno placentario y pruebas positivas a autoanticuerpos. (Cowchock S. Autoantibodies and pregnancy loss. N Engl J Med 1997;337:197-198).

\section{Efectos de la administración de cinc sobre el desarrollo del niño}

Los seres humanos obtienen el cinc principalmente de las carnes y otros alimentos de origen animal, que en países como Guatemala son de difícil acceso para la población rural debido a su elevado costo. Por lo tanto, muchos niños guatemaltecos padecen de una deficiencia de cinc, trastorno que se ha asociado con el mal apetito y con una ingesta disminuida de productos ricos en este nutriente. Movidos por la hipótesis de que ese déficit también podría ser causa de una menor actividad motora, Bentley et al. administraron $10 \mathrm{mg}$ diarios de sulfato de cinc durante 7 meses a 85 niños guatemaltecos de 6 a 9 meses de edad. El desarrollo motor y el tiempo en que los niños fueron observados en varias posiciones (cargados, acostados, sentados, gateando, de pie, o caminando) y actividades (comiendo, durmiendo, descansando, llorando, o jugando) fueron comparados con los de otro grupo de niños que recibió placebo. Aunque no se observaron diferencias del desarrollo motor, el seguimiento a los 7 meses reveló que los niños cuya dieta había sido suplementada con cinc eran más activos y lloraban menos que los del grupo control. Estos efectos no mostraron ninguna asociación con otros factores, tales como edad, desarrollo motor, sexo, escolaridad materna, situación socioeconómica de la familia, o estado nutricional. Según los autores, la confiabilidad de los resultados estuvo asegurada por la naturaleza aleatoria del ensayo a doble ciego, el ámbito doméstico en que se efectuó la actividad, el adiestramiento de los observadores con controles periódicos de la calidad de los datos, el uso 
de un instrumento adecuado para Guatemala y el análisis estadístico de los datos, con ajustes para corregir el efecto de posibles variables de confusión.

Los resultados obtenidos concordaron parcialmente con los de estudios previos en que se había detectado un aumento de la actividad o del desarrollo motor tras la administración de cinc en monos rhesus, en lactantes nacidos con bajo peso y en niños de 12 a 24 meses de edad en la India. Ante el hecho de que la administración de cinc durante 7 meses produjo un efecto favorable significativo en la actividad del niño, manifestado particularmente en forma de una mayor tendencia al juego, cabe esperar que también tenga un efecto beneficioso a largo plazo sobre otros parámetros evolutivos del niño, tales como su desarrollo cognoscitivo. (Bentley ME, Caufield LE, Ram M, Santizo MC, Hurtado E, Rivera JA, et al. Zinc supplementation affects the activity patterns of rural Guatemalan infants. J Nutr 1997;127:373-378).

\section{Déficit de folato y síntomas de depresión}

De todos los déficit nutricionales que pueden producir perturbaciones neuropsiquiátricas, el de folato es el que más se vincula con cuadros depresivos. Dadas la probable participación del folato en los procesos metabólicos del sistema nervioso central (SNC) y la posibilidad de administrarlo como suplemento nutricional, Alpert y Fava efectuaron una revisión del tema y examinaron las pruebas acumuladas en las últimas décadas de la existencia de una relación entre la deficiencia de folato por un lado y la regulación del estado de ánimo y los efectos de los medicamentos antidepresivos por el otro.

Comparados con otros pacientes psiquiátricos o con individuos normales, los pacientes deprimidos manifiestan menores concentraciones de folato en suero $(\leq 2,5 \mathrm{ng} / \mathrm{mL})$ o en glóbulos rojos $(<200 \mathrm{ng} / \mathrm{mL})$. Además, cuando las concentraciones son muy reducidas, los síntomas de depresión son más acentuados. Desde 1970 se viene observando que los pacientes con bajas concentraciones de folato responden menos al tratamiento antidepresivo, sea a base de terapia electroconvulsiva, fármacos antidepresores, o triptófano. Más recientemente se ha observado un fenómeno similar en casos tratados con fluoxetina, sertralina y nortriptilina. Consiguientemente, la detección de bajas concentraciones de folato en suero y glóbulos rojos presagia una respuesta inadecuada al tratamiento antidepresivo.

En ensayos a doble ciego en que se administraron diariamente $200 \mu \mathrm{g}$ de ácido fólico a pacientes tratados con litio, se logró reducir la frecuencia y la duración de los episodios de depresión; aun cuando se recurrió a un derivado, el metilfolato, se obtuvo una mejor respuesta al tratamiento estándar. Todos estos datos sugieren que el folato o el metilfolato está indicado como suplemento de la farmacoterapia antidepresiva e incluso como tratamiento único en pacientes con bajas concentraciones de folato en suero y glóbulos rojos. Falta determinar su eventual idoneidad para otros usos en neuropsiquiatría, tales como la regulación del estado de ánimo, del apetito, de los niveles de energía y de la concentración.

Aparentemente, la administración de folato debe limitarse a bajas dosis, ya que con $15 \mathrm{mg}$ diarios en voluntarios sanos se han comprobado efectos nocivos (alteración del sueño, malestar, irritabilidad e hiperactividad). Una amplia variedad de factores y condiciones, incluidos determinados medicamentos (anticonvulsivos, anticonceptivos orales y quimioterapias anticancerosas), síndromes de malabsorción intestinal, alteraciones autoinmunitarias, errores congénitos del metabolismo, alcoholismo, embarazo y dietas pobres en folato, se asocian con estados de déficit. Se ignora si esa deficiencia es la causa de la depresión o si la escasa alimentación característica del cuadro depresivo es la responsable de la disminución de las concentraciones de folato. Se ha especulado que una combinación de falta de apetito, hipoabsorción y aumento de las necesidades orgánicas podría llevar a una depleción de folato con una eventual repercusión sobre el SNC. En otros pacientes, tales como los alcohólicos, la deficiencia podría predisponer a un estado depresivo. En cambio, en individuos persistentemente deprimidos, la pérdida del apetito y la elección inadecuada de alimentos contribuirían a reducir las concentraciones de folato y ello a su vez exacerbaría la depresión y reduciría la eficacia del tratamiento estándar.

Aunque las hipótesis que vinculan la deficiencia de folato con la depresión requieren mayor fundamentación empírica, en la actualidad las pruebas son suficientes para recomendar la medición de las concentraciones de folato en sujetos con depresión aguda y crónica, particularmente si se muestran refractarios al tratamiento. En tales casos, la suplementación con folato o metilfolato podría resultar útil. (Alpert JE, Fava M. Nutrition and depression: the role of folate. Nutr Rev 1997;55:145-149).

\section{Trascendencia del análisis genómico de Helicobacter pylori}

La labor realizada por Tomb et al., quienes lograron secuenciar en su totalidad el genoma de la bacteria Helicobacter pylori, ha suscitado un interés justificado debido a sus implicaciones clínicas. Desde comienzos de siglo la úlcera péptica se había relacionado con el estrés, factores dietéticos e hiperacidez gástrica. Por consiguiente, la hipótesis de que la enfermedad fuera causada por una bacteria, según plantearon Warren y Mar- 
shall en 1983, fue inicialmente recibida con escepticismo. $\mathrm{Al}$ año siguiente, sin embargo, Hugh et al. publicaron los resultados de un estudio epidemiológico sobre las variaciones de la incidencia de úlcera péptica en diferentes estados australianos, demostrando con ello su relación con factores ambientales, como la contaminación del agua de consumo. Posteriormente, la comprobación de que $H$. pylori, microorganismo flagelado gramnegativo que se recupera de casi la mitad de la población en el mundo, posee una enzima que le permite sobrevivir a un $\mathrm{pH}$ ácido y colonizar la mucosa gástrica, dio lugar a un creciente número de investigaciones que, en su conjunto, han revolucionado conceptos tradicionales acerca de la fisiología gástrica, sus alteraciones y los tratamientos adecuados. La presencia de la bacteria en la mucosa intestinal se asocia con una gastritis crónica activa y, por ende, con enfermedades más graves, incluida la gastritis atrófica crónica (precursora de los carcinomas gástricos), la úlcera péptica y los linfomas gástricos.

Se sabe que muy pocos microorganismos sobreviven en ambientes hiperácidos, pero la potente ureasa propia de $H$. pylori le permite a esta bacteria sobrevivir en esas condiciones. De ahí que la ureasa, principal elemento antigénico de la bacteria, constituya un factor de referencia conveniente para el diagnóstico. Muchas de las investigaciones que todo esto ha generado actualmente pueden evaluarse en su verdadero contexto, dada la información aportada por el análisis genómico de H. pylori. En virtud de su importancia como agente patógeno humano y del interés que revisten su biología y evolución, la secuenciación genómica de H. pylori que han logrado Tomb et al. abre nuevas perspectivas para un mejor conocimiento de su patogenia, su tolerancia a un medio ácido, su variación antigénica y su carácter microaerófilo. Más aún, el establecimiento de factores que determinan su virulencia permitiría precisar los mecanismos asociados con la colonización inicial, su persistencia a largo término y la promoción de diversas enfermedades gastroduodenales, para sobre esa base planificar el diseño de medicamentos adecuados y el desarrollo de vacunas específicas. (Tomb J-F, White $\mathrm{O}$, Kervalage AR, Clayton RA, Sutton GG, Fleishmann RD, et al. The complete genome sequence of the gastric pathogen Helicobacter pylori. Nature 1997;338:539-547).

\section{Resultados promisorios de una vacuna anticólera}

El cólera continúa siendo un importante problema de salud pública en casi todos los países en desarrollo. Si bien mejores condiciones sanitarias y buenos abastecimientos de agua potable pueden eventualmente ayudar a controlar la transmisión de Vibrio cholerae, la vacunación eficaz sería extremadamente útil para limi- tar la morbilidad y mortalidad. A ese efecto se han desarrollado vacunas orales a base de vibriones muertos y vivos atenuados, con ventajas y desventajas en ambos casos. De las vacunas orales elaboradas con vibriones vivos, la más prometedora parece ser la Perú-15, que contiene una cepa mutante derivada de la denominada El Tor Inaba y por lo tanto similar a la cepa causal de la pandemia actual. Continuando estudios de Kenner et al., cuyos resultados fueron publicados en 1995, Sack et al. han evaluado la vacuna Perú-15 en la Unidad de Control de Vacunas de la Universidad Johns Hopkins en Baltimore, Maryland, Estados Unidos de América. Doce voluntarios de 18 a 50 años fueron internados en el Centro de Investigación Clínica del hospital de esa institución para recibir $10^{7}$ ó $10^{9}$ unidades formadoras de colonias de una vacuna fresca de reciente preparación. La hospitalización posibilitó que los voluntarios fueran tratados con doxicilina desde el sexto día y controlados dos veces al día hasta su egreso, que fue autorizado cuando el coprocultivo arrojó resultados negativos. Posteriormente, 50 voluntarios externos recibieron dosis de $10^{8}$ ó $10^{9}$ unidades de vacuna, en esta ocasión liofilizada y reconstituida, o placebo.

La cepa Perú-15 fue bien tolerada a todas las dosis empleadas y estimuló la aparición de títulos elevados de anticuerpos antivibrión en la mayoría de los voluntarios internados y en todos los voluntarios externos. Aunque la detección de anticuerpos antitoxina fue menos frecuente en estos grupos y la intensidad de la respuesta menor de la observada habitualmente en casos de enfermedad, se encontraron dichos anticuerpos en más de $60 \%$ de los voluntarios externos. Alrededor de $60 \%$ de todos los voluntarios (internos y externos) excretaron por las heces las cepas usadas en la vacuna, sin que hubiera ninguna correlación serológica, ya que voluntarios con coprocultivos negativos tuvieron anticuerpos antivibrión y antitoxina con igual frecuencia y en igual cantidad que los que tuvieron coprocultivos positivos.

Se concluye que la cepa Perú-15 indujo una respuesta serológica similar a la suscitada por la CVD 103 $\mathrm{Hg}-\mathrm{R}$, vacuna oral a base de vibriones vivos atenuados cuyo uso está autorizado en Europa, Canadá y América del Sur. De ahora en adelante, correspondería llevar a cabo estudios para comparar las dos vacunas y evaluar los resultados de una dosis subsiguiente de $V$. cholerae, ya que sería la forma de determinar el grado de protección a largo plazo. La posibilidad de que los genes responsables de la toxicidad puedan transferirse de una cepa a otra por mediación de un bacteriófago filamentoso fue descartada en el caso de la cepa Perú-15 dada la naturaleza de las mutaciones genéticas definidas que contribuyen a su atenuación. Por otra parte, la descontaminación de las heces que formó parte del presente estudio tuvo por objetivo evitar la diseminación prematura de una cepa con nuevas características genéticas en el medio ambiente. En las condiciones establecidas, no 
habría posibilidad de efectos adversos importantes, ya que el fenotipo de las cepas liberadas al exterior del organismo se mantendría inalterado. (Sack DA, Sack RB, Shimko J, Gomes G, O'Sullivan D, Metcalfe K, et al. Evaluation of Peru-15, a new live oral vaccine for cholera, in volunteers. J Infect Dis 1997;176:201-205).

\section{Aparición de resistencia a los fármacos antirretrovirales disponibles}

La aparición de resistencia en pacientes tratados con zidovudina durante 6 meses fue descrita inicialmente en 1989; hacia 1995, sobre la base de datos corroborados in vitro, se había observado resistencia a todos los medicamentos empleados como tratamiento de la infección por virus de la inmunodeficiencia humana (VIH). En su revisión bibliográfica, Nájera Morrondo clasifica esos fármacos en tres grupos - nucleósidos inhibidores de la transcriptasa inversa (zidovudina, didanosina, zalcitabina, stavudina y lamivudina); inhibidores de la transcriptasa inversa no nucleósidos (nevapirina, delavirdina, lovirida y atevirdina), e inhibidores de la proteasa (saquinavir, ritonavir, indinavir, nelfinavir y SC-55389A) - , a la vez que destaca las mutaciones virales más puntuales y la alta resistencia que confieren (de 10 a 1000 veces mayor).

Se definen varios conceptos clave respecto de los inhibidores de la transcriptasa inversa, como el de resistencia natural, que es consecuencia de la enorme variabilidad genética del virus y de la gran dinámica viral que se produce con la progresión de la enfermedad. La resistencia cruzada se describe como un fenómeno producido cuando una población de virus resistentes a un medicamento antirretroviral muestra resistencia a otros medicamentos con los que no ha entrado en contacto. El fenómeno de resensibilización ocurre cuando la presencia de una mutación que confiere resistencia a un fármaco permite recuperar la sensibilidad perdida a otro. En el caso de los inhibidores de la proteasa, se ha comprobado la existencia de distintos modelos de resistencia, entre ellos la de tipo natural. Cuando se acumulan varias mutaciones, se obtiene un alto grado de resistencia (mayor de 100 veces) y se producen resistencias cruzadas. (Nájera Morrondo A. Epidemiología de las resistencias a los antirretrovíricos. Pub Of SEISIDA 1997;8:16-20).

\section{Probable contaminación del agua de consumo por Toxoplasma}

La toxoplasmosis, parasitosis endémica en todo el mundo, adopta por lo general formas subclínicas o leves, aunque en mujeres embarazadas suele ser causa de malformaciones congénitas y en pacientes inmunodeprimidos sus manifestaciones suelen ser graves. Debido a la rara frecuencia de focos de toxoplasmosis que se extiendan más allá de una familia o de un grupo pequeño, Bowie et al. destacan las peculiaridades del foco que llegaron a observar en una provincia canadiense, tanto por su extensión como por su probable vinculación con el agua de consumo. En marzo de 1995, el Centro para el Control de Enfermedades de Columbia Británica, Canadá, detectó un súbito aumento de la incidencia de toxoplasmosis en partes de la ciudad de Victoria y de sus alrededores en la isla de Vancouver con una mezcla de zonas urbanas, suburbanas y rurales. Ese incremento fue detectado por el único laboratorio de la provincia que realizaba el diagnóstico serológico de la infección por Toxoplasma gondii, al mismo tiempo que dos oculistas notificaron de forma independiente la aparición de siete casos de toxoplasmosis aguda con retinitis. Se inició entonces un tamizaje serológico, llegándose a identificar 100 casos agudos relacionados con el brote. Todos estaban concentrados en la zona central de la provincia, sin que hubiera pruebas de transmisión por consumo de carne, verduras o productos lácteos contaminados. De ahí que los estudios se centraran en el servicio de agua de consumo, que en esa época proveía agua clorada sin filtrar a 292000 personas pertenecientes a una población total de 321585 . La curva epidémica presentó dos picos (diciembre de 1994 y marzo de 1995) precedidos de un aumento de las lluvias y de la turbidez del agua en una de las represas. No pudo establecerse fehacientemente que esa represa fuera la responsable del brote, puesto que la recolección de las muestras para análisis se inició a los 3 meses de haberse detectado el último caso. Es probable que el agua ya estuviera contaminada por ooquistes de $T$. gondii, puesto que cuatro de siete gatos recogidos en los alrededores de la represa y cinco pumas atrapados en la isla de Vancouver mostraron anticuerpos. Un gato infestado puede liberar 200 millones de ooquistes capaces de sobrevivir en aguas a 3 a $18{ }^{\circ} \mathrm{C}$, que era la temperatura de la represa en el momento de la epidemia. Por otra parte, el cambio rápido del agua al efectuarse la adición de cloro habría impedido la sedimentación de los quistes, en tanto que la falta de filtración pudo haber posibilitado el ingreso de $T$. gondii a la red de distribución.

En última instancia, el brote demostró la importancia que reviste un buen sistema de salud pública, ya que el programa de pesquisa serológica temprano redujo el impacto del brote y sus costos a largo término y permitió recoger información que condujo al cierre de la represa sospechada. (Bowie WR, King AS, Werker DH, Issac-Renton JL, Bell A, Eng SB, et al. Outbreak of toxoplasmosis associated with municipal drinking water. Lancet 1997;350:173-177). 


\section{Características socioculturales del portador de hidatidosis}

A partir de 1992 se desarrolló en una población chilena presuntamente sana un estudio diagnóstico sobre hidatidosis cuyo objetivo fue averiguar si determinados rasgos socioculturales podían asociarse con la condición de portador. Usando una muestra aleatoria constituida por 2823 personas aparentemente sanas procedentes de zonas rurales (provincias de Cauquenes y Linares), se llevó a cabo un examen serológico mediante técnicas de inmunoensayo enzimático (ELISA) simple, inmunodot y hemaglutinación indirecta. Por las tres técnicas, 30 personas dieron resultados positivos. Sobre la base de la encuesta epidemiológica por entrevista, el estudio comparado de las variables epidemiológicas de los 30 infectados y 53 controles serológicamente negativos arrojó los siguientes resultados respectivos: analfabetismo, $13,3 \%$ frente a 1,9\%; escolaridad básica, $56,7 \%$ frente a $81,1 \%$, y posesión de perros infestados por Echinococcus granulosus, $46,7 \%$ frente a $20,8 \%$. En cambio, la práctica de alimentar a los perros con vísceras afectadas por quistes hidatídicos fue mucho más frecuente en los controles $(85,1 \%)$ que en los individuos infectados $(59,2 \%)$. Al examinarse el resto de las variables (características demográficas, recepción de información por los medios de comunicación en masa, hábitos alimentarios malsanos, matanza domiciliaria de animales para consumo casero y conocimientos sobre la hidatidosis), no se encontraron asociaciones estadísticamente significativas.

Galdamez et al. no llegaron a definir el carácter global de las variables socioculturales asociadas con la condición de ser o no presunto portador. No obstante, indicaron que un estudio sobre factores inmunobiológicos y ambientales y sobre hábitos y conductas permitiría diseñar un programa adecuado para la prevención de la hidatidosis, orientado hacia determinados puntos vulnerables en la región VII, que es una de las cuatro zonas de Chile con las mayores tasas de incidencia, prevalencia y mortalidad. (Galdamez O, Cortés O, Vargas D, Rodríguez J, Vega F, Pérez C, et al. Variables epidemiológicas asociadas a hidatidosis en población rural asintomática. Parasitol Dia 1997;21:7-13). 